\title{
Pensar en el sentido de la vida es orar
}

Edgar Enrique Velásquez Camelo

Pontificia Universidad Javeriana, Colombia 


\title{
Pensar en el sentido de la vida es orar*
}

Resumen: La filosofía y la teología han tenido como telón de fondo la cuestión del ser humano; la filosofía desde un enfoque de complejidad y la teología desde la óptica de la revelación. Tiene sentido preguntarnos acerca de la necesidad que tiene la persona de resolver, de forma progresiva, la pregunta por el sentido de la vida por medio del cultivo de la inteligencia espiritual; de tal forma que se reconozca el papel que tiene la oración, como ejercicio espiritual, en la toma de decisiones, cuya orientación permite conducir la vida en el mundo actual.

Palabras clave: sentido de la vida, oración, inteligencia espiritual, pensamiento, acción.

\section{Thinking about the sense of life is to pray}

\begin{abstract}
Philosophy and Theology have had, as a backdrop, the question for the human being; Philosophy from an approached complexity and Theology from the perspective of Revelation. This has the sense of asking ourselves about the necessity for any person to solve, in a progressive way, the question about the meaning of life through the cultivation of spiritual intelligence in such a way that, the role of prayer, as a spiritual exercise and in decision-making, is recognized, whose orientation allows us to lead life authentically in today's world.
\end{abstract}

Keywords: sense of life, prayer, spiritual intelligence, thought, action.

Fecha de recepción: 19 de julio de 2019

Fecha de aceptación: 11 de diciembre de 2019

Forma de citar (APA): Velásquez-Camelo, E. E. (2020). Pensar en el sentido de la vida es orar. Revista Filosofía UIS, 19(2), https://doi.org/10.18273/revfil.v19n2-2020004

Forma de citar (Harvard): Velásquez-Camelo, E. E. (2020). Pensar en el sentido de la vida es orar. Revista Filosofía UIS, 19(2), 55-73.

Edgar Enrique Velásquez Camelo: colombiano. Licenciado en Filosofía y Letras de la Universidad Pontificia Bolivariana, Colombia.

ORCID iD: 0000-0003-1359-3848

Correo electrónico: edgar.velasquez@javeriana.edu.co, evelasquez@sdbcob.org

*Artículo de reflexión derivado de investigación.

Revista Filosofía UIS, vol. 19 n. ${ }^{\circ}$ 2, julio - diciembre 2020 


\title{
Pensar en el sentido de la vida es orar
}

\begin{abstract}
El mismo Abad Antonio investigando la profundidad de los juicios de Dios, rogó diciendo: "Señor, ¿Por qué mueren algunos tras una vida corta y otros llegan a la extrema vejez? ¿Por qué algunos son pobres y otros ricos? ¿Por qué los injustos se enriquecen y los justos pasan necesidad?" Entonces vino hasta él una voz que le respondió: "Antonio, ocúpate de ti mismo, pues eso es el juicio de Dios, nada te aprovecha el saberlo". (Elizalde, 1986, p. 15)
\end{abstract}

\section{Introducción}

El objetivo de esta investigación es entender por qué pensar en el sentido de la vida es orar, es decir, involucra la inteligencia espiritual (Torralba, 2018, p. 43). Esto con el fin de comprender cómo resolver la pregunta por el sentido desde la capacidad de la oración como condición necesaria que facilita la indagación existencial por la autenticidad y la plenitud. ¿Es la oración, desde la inteligencia espiritual, una forma para responder a la pregunta por el sentido de la vida? La tesis que se defiende en este escrito es que el sentido de la vida está íntimamente ligado a la capacidad de la oración, dirigida por la inteligencia espiritual como disposición interior de la persona, que le permite escudriñar el fondo de su ser e ir más allá y la posibilidad misma de la trascendencia. Si la pregunta por el sentido de la vida se resuelve, en gran medida, por la inteligencia espiritual, tiene sentido que pensar en ella es, a la vez, orar, como un ejercicio de introspección esencial que vincula la vida con la acción, la vivencia y la capacidad de la donación.

Para desarrollar lo anterior proponemos el siguiente esquema argumentativo: en el primer apartado se cuestiona qué significa pensar la vida en el mundo de hoy. Esto es, poner en tela de juicio el pensar la vida en un mundo fragmentado y aparente (Velásquez, 2017b), cuya representación se funda en el modelo virtual de interacción social. El segundo apartado presenta una perspectiva sobre el papel que cumple la inteligencia espiritual en nuestras vidas y su concretización en el ejercicio espiritual de la oración como la capacidad de "tomar distancia" de la vida (Torralba, 2018, p. 94). A modo de conclusión, el tercer apartado sustenta cómo la actividad del pensamiento sobre el sentido de la vida está íntimamente ligado a la capacidad de la oración como un distanciamiento que, en la interacción con lo 
otro, la persona puede comprenderse cada vez más a sí misma (Ricoeur, 2015b, p. 21), proyectarse en el mundo y resolver, de manera progresiva, la indagación existencial por el sentido (Frankl, 2003, pp. 30-31).

\section{Pensar la vida en el mundo contemporáneo}

La pregunta por el sentido de la vida es una indagación noética y existencial fruto de la epimeleia heautou (Inquietud de sí) (Foucault, 2014, pp. 28-29). La resolución progresiva y dinámica del sentido de la vida es el asunto donde están implicados procesos intelectuales que permiten la toma de distancia de la vida cotidiana (Foucault, 2014, p. 33). Pensar la vida en el mundo contemporáneo no es fruto de la mera especulación reflexiva de corte trascendental, sino que sucede en el plano inmanente de la existencia en relación con las múltiples formas de la alteridad (Ricoeur, 2006); dicho de otra manera, la comprensión de la vida es un asunto hermenéutico existencial. Paul Ricoeur (2015b) dice en El conflicto de las interpretaciones: "toda hermenéutica es, explícita o implícitamente, comprensión de sí por el desvío de la comprensión del otro" (p. 21). Así las cosas, no podemos eludir el pensamiento sobre la vida porque ella es en esencia comprensión, como lo afirma Martín Heidegger en El ser y el tiempo (2018).

Ahora bien, ¿qué se entiende por oración? Desde el punto de vista antropológico el ser humano es un ser espiritual (Segundo, 1982, p. 119). No se puede desconocer la dimensión espiritual del ser humano ni mucho menos menospreciar el valor del cultivo de la vida espiritual, incluso en una sociedad que polemiza, por el influjo del positivismo en el pensamiento cotidiano no especializado (Heller, 1998), los beneficios de las prácticas o ejercicios espirituales al no ofrecer soluciones de tipo práctico, sino una ayuda de tipo hermenéutico (Heidegger, 2002, p. 19). La oración no es patrimonio exclusivo de alguna religión o credo (Torralba, 2018, p. 228), pertenece a la herencia espiritual de la humanidad y se constituye en el modo esencial para que la persona pueda ejercitar la inteligencia espiritual y resolver la progresiva y dinámica indagación por el sentido.

La oración es un ejercicio espiritual que permite a la persona auscultar la Ilamada interior, como lo dice Torralba (2018), vocatio, en lo más recóndito de la persona (pp. 166-171). No hay un modo específico de orar, sino diversas maneras de ejercitar el cultivo de la vida espiritual, cuyos senderos conducen a la oración como posibilidad interior hacia el sentido de la vida, que no es otra cosa que la responsabilidad objetiva de los motivos que animan a la persona a precursar por este mundo (Frankl, 2010, p. 15).

Si la oración es condición de posibilidad para la indagación existencial por el sentido, esto requiere, como garantía del cultivo de la vida espiritual: el silencio, 
la meditación y la serenidad. El silencio constituye una exigencia para quien desea desarrollar los potenciales de la inteligencia espiritual. Torralba reconoce en esta práctica espiritual el ámbito existencial que permite el florecimiento de la situación real de la persona, asimismo, proporciona al ser humano la capacidad de trascender y descubrir en el fuero interno de su conciencia las preguntas esenciales de la vida acerca del sentido y el significado de la realidad:

El silencio es un ámbito especialmente idóneo para la irrupción de preguntas y de experiencias que están íntimamente conectadas con la vida espiritual. Cuando uno está en silencio consigo mismo y logra acallar las voces de la mente, se asombra de la realidad, experimenta el misterio de todo lo que hay y palpita en él, con ímpetu, la pregunta por el sentido. [...] El silencio juega un papel decisivo para la práctica de la oración, de la meditación, del encuentro con Dios y con el mundo. (Torralba, 2018, p. 197)

En el silencio, además, acontece dentro de sí la llamada del interior que determina en gran medida la orientación vocacional en el reconocimiento de las posibilidades existenciales y a la vez de los potenciales y las limitaciones. La persona, en su individualidad, responde con su sí-respondiente en la inmanencia de la vida hacia la proyección de su especificidad vocacional. Así lo expresa Paul Ricoeur en Amor y justicia desde la figura del profeta bíblico veterotestamentario que responde al Ilamado del Señor: "si se pregunta quién llama, es preciso decir que en la conciencia el Dasein se llama a sí mismo; dicho de otro modo, el llamado de la conciencia no es otra cosa que el Ilamado de la inquietud" (Ricoeur, 2015a, p. 115). No se trata de un autollamado sino de la convocación que acontece en el interior de la persona y que solo puede ser escuchada en el silencio.

Así también lo hace notar Michel Foucault (2014) al presentar el silencio como una práctica espiritual que permite a la persona el reconocimiento de sí y de las posibilidades de proyección humana en el mundo (p. 351). Entonces el silencio no es mutismo, sino más bien una disposición interior que facilita el esclarecimiento existencial de las perspectivas de proyecto latentes en el interior del ser humano. No siempre resulta fácil el reconocimiento de sí en la actualidad, y más cuando la persona está al asecho de los ritmos de vida acelerados (Francisco, 2015, párr. 18), al bombardeo informático virtual (Velásquez, 2017a, p. 63), y las diferentes modalidades del bullicio existencial que atrofian la vida espiritual (Torralba, 2018, p. 278).

El silencio, al ser una disposición interior, debe acontecer de forma espontánea en la persona durante la práctica espiritual de la oración. Solo en el reconocimiento de sí a través del silencio, afirma Torralba (2018), es posible entender el sentido de la vida (p. 197). No se trata de especulación acerca del significado de la existencia humana, sino más bien, de un asunto esencial en la vida del ser humano. El sentido de la vida, como afirma Victor Frankl (2010), surge en una persona que ha 
logrado ser responsable de su propia existencia y, de esta manera, direccionar la vida de forma loable en el mundo (p. 15).

La meditación, como parte esencial de la oración, es un ejercicio ligado al silencio. Diversas corrientes o filosofías espirituales, sobre todo orientales, destacan de forma admirable los beneficios de la meditación (Torralba, 2018, p. 227). Según Michel Foucault, la meditación en la actualidad se restringe al pensamiento superficial de un tema, sin llegar a tocar la existencia del ser humano (2014, pp. 338-339). Desde Torralba esta práctica espiritual es mucho más que un ejercicio cognitivo, porque en ella se ve implicada no solo un tema, sino la persona en su totalidad:

Cuando uno medita atentamente un texto, no se limita a leerlo. Lo relee cíclicamente con el objetivo de que la idea se vierta en él, cale en lo más hondo del propio ser. La meditación de los textos, de las palabras y de las sentencias de los grandes maestros espirituales de la humanidad es uno de los modos más eficaces de desarrollar la inteligencia espiritual. El objetivo final no es comprender; sino integrar y asumir en el propio ser el objeto de la meditación. (Torralba, 2018, pp. 228-229)

La meditación, si bien se centra en un tema, no se limita a la captación cognitiva que sucede en la comprensión, como si tratara de un ejercicio de análisis textual. Una verdadera meditación, según Torralba, tiene que ir a lo hondo del ser humano y provocar, si es necesario, los cambios pertinentes para una mejor calidad de vida. Si la meditación se tratara solo de comprender, no tendría la persona ningún beneficio más que el de ampliar su conocimiento sobre un tema. La meditación va mucho más allá: implica. En términos de Paul Ricoeur (2001), la implicación existencial con el mundo del texto desde la hermenéutica de la apropiación (p. 109).

Así las cosas, la meditación junto con el silencio, en el escenario específico de la oración, permiten a la persona esclarecer las opciones fundamentales de la vida, el sentido y significado de la existencia y, de esta forma, descubrir el lugar que debe ocupar en el mundo. Ahora bien, la oración desde el silencio y la meditación quedaría como una práctica vacía si no viene acompañada por la serenidad. Esta se convierte en la alternativa espiritual ante el asedio de un mundo tecnificado (Heidegger, 2002, p. 21) que no permite, en todo su sentido, el desarrollo de la inteligencia espiritual.

Heidegger ha sido uno de los filósofos que ha desarrollado el concepto de serenidad como fruto del pensamiento reflexivo (2002). Se entiende por serenidad la situación existencial de la persona, como fruto del silencio y la meditación durante el ejercicio espiritual de la oración; la serenidad, entonces, es resultado del cultivo de la vida espiritual. Pero, advierte Torralba (2018), que 
no se trata de algo accesorio, como una herramienta que aplaca los reclamos de la conciencia moral, ni tampoco un estado psicológico (p. 286). La serenidad es el culmen del cultivo de la vida espiritual y, desde la meditación y el silencio, es condición de posibilidad para la oración. Así, cuando la persona esté al asecho de los inconvenientes de la vida, ante el sinsentido y las contradicciones que enfrente en la cotidianidad, esta logrará mantenerse ecuánime por la serenidad que ha cultivado en la oración por medio de la meditación y el silencio.

Torralba, al presentar la inteligencia espiritual, enseña que 'el dulce no hacer nada' es una expresión del desarrollo de la vida espiritual y correlativa a la idea de serenidad:

La aceleración tecnológica, el portentoso acortamiento del tiempo en la fabricación y la venta de productos, los cambios cada vez más veloces en los gestos, las modas, los estilos de vida, generan una imagen del mundo como algo muy efímero. Nadie puede negar que, principalmente en las grandes urbes, se vive vertiginosamente. [...] El no hacer nada, contrariamente a lo que se pueda pensar, no es estéril, ni vacío. Es la ocasión ideal para activar la inteligencia espiritual, para buscar el sentido a las cosas y experimentar el misterio de la realidad. (Torralba, 2018, pp. 218-219)

Si la sociedad actual, con sus dinámicas de producción-consumo-producción del capitalismo informacional (Velásquez, 2019, p. 248), no permite la toma de distancia y, por tanto, la oración no deja de ser un momento superficial y efímero es porque dichas dinámicas sociales se han convertido en su notable impedimento (Horkheimer y Adorno, 1998). La serenidad para con las cosas, como lo dice Heidegger (2002), nos salva del dominio de la técnica y facilita el ejercicio del pensamiento reflexivo (p. 30). De lo contrario, la persona queda avocada al vacío y al sinsentido que provoca no pocas veces la desesperación frente a la vida.

Sería necio arremeter ciegamente contra el mundo técnico. [...] Dependemos de los objetos técnicos; nos desafían incluso a su constante perfeccionamiento. Sin darnos cuenta, sin embargo, nos encontramos tan atados a los objetos técnicos, que caemos en relación de servidumbre con ellos. [...] Pero también podemos hacer otra cosa. Podemos usar los objetos técnicos, servirnos de ellos de forma apropiada, pero manteniéndonos a la vez tan libres de ellos que en todo momento podamos desembarazarnos (loslassen) de ellos. [...] Podemos decir «sí» al inevitable uso de los objetos técnicos y podemos a la vez decirles «no» en la medida en que rehusamos que nos requieran de modo tan exclusivo, que dobleguen, confundan $y$, finalmente, devasten nuestra esencia. (Heidegger, 2002, p. 27-28)

La serenidad, vista de este modo, no es simplemente un estado psicológico o el apaciguamiento de la conciencia; ante todo, es una actitud frente a la vida, que orienta las decisiones frente a las varias propuestas que confunden el sentido. Al 
buscar la serenidad, la persona hace una apuesta por una vida simple (Velásquez, 2019, p. 247), libre de las expectativas de vida de la sociedad de consumo, de las tendencias de vida aparente y superficial (Velásquez, 2015, p. 518), que conducen a la persona a la anulación de toda expresión de vida espiritual (Velásquez, 2018, p. 102). Si, por el contrario, una persona es capaz de vivir en serenidad para con las cosas, en el sentido de Heidegger, por medio del silencio y la meditación, podrá vivir de forma tranquila frente a las vicisitudes diarias. No siempre es bien apreciada la serenidad porque exige de parte de la persona el cultivo de hábitos de vida espiritual, tomarse en serio la vida y atreverse a pensar el sentido y significado de la existencia (Heidegger, 2002, p. 17). De ahí que, dice Torralba (2018), sea un arduo trabajo frente a las dinámicas envolventes y muchas veces esquizofrénicas de la sociedad contemporánea (p. 278).

Al igual que Torralba, Foucault (2014) considera que el objeto de las prácticas espirituales es asumir la vida como una prueba (p. 415). Esta comprensión clásica del cultivo de la vida espiritual permite entender la función de la sabiduría en la persona: entender el sentido de la vida, el sufrimiento (Ricoeur, 2008, pp. 185189), el dolor y reconocer las posibles perspectivas de proyecto latentes al interior de la persona y que solo pueden salir a la luz, según Torralba, por medio de la inteligencia espiritual (2018).

Ahora bien, la vida espiritual pertenece a un modo existencial dada la naturaleza racional del ser humano. Si hablamos de pensamiento y oración es porque allí residen, en su forma específica, según cada persona, los modos concretos en que la oración se convierte en el facilitador de la indagación por el sentido y fin de la existencia. No pensar la vida es negarse a entender su sentido. Dicho de otra manera, solo a través del pensamiento se logra en la oración esclarecer la vida y su significado. Sin embargo, como podemos evidenciar junto con Torralba, el mundo social sufre lo que el Papa Francisco (2015) Ilama, en Laudato Si', rapidación social, que afecta los ritmos de vida de la persona (párr. 18).

En esas condiciones, donde las personas tienen que resolver los asuntos de supervivencia cotidiana y atender las múltiples preocupaciones propias de la vida en los variados escenarios vitales, el pensamiento y la oración se convierten en asuntos irrelevantes porque no ofrecen una solución práctica e inmediata a los problemas reales que padece la sociedad en general (Heidegger, 2002, p. 19). Las personas están más preocupadas por sobrevivir que por vivir (Francisco, 2015, párr. 46), y esto se debe, en gran medida por la injusticia social, a las expectativas altas de la sociedad de consumo (Velásquez, 2015, p. 521) y a la rapidación de las dinámicas del mundo social de producción (Velásquez, 2019, p. 249).

De ahí se puede entender el carácter plausible de la vida espiritual en la persona. Se entiende por plausible lo que de por sí es derrotable. El carácter 
derrotable de la vida espiritual por medio de la oración en el silencio, la meditación y la serenidad, se debe a su misma exigencia (Heidegger, 2002, p. 20). Solo aquellos aventureros del espíritu, por retomar la expresión de Fernández Artime, son capaces de adentrarse en los mares profundos de la vida y bucear hacia lo más recóndito de la persona, para que desde allí descubra al mundo sus potenciales más propios. El ser humano es suficiente y, a la vez, finito y carente (Ricoeur, 2011).

El cultivo de la inteligencia espiritual se convierte en el modo noético y existencial para reconocer la suficiencia y finitud del sentido, cuya demanda espiritual reclama esfuerzo y dedicación (Torralba, 2018, p. 61; Foucault, 2014, pp. 222-223). En asuntos de vida espiritual, según Torralba (2018), o se obtienen beneficios o se conduce hacia la atrofia existencial (p. 263). Si la persona ejercita su vida espiritual podrá obtener sus beneficios, pero si no hay una disposición para el entrenamiento en la oración desde el silencio, la meditación y la serenidad, no podrá descubrir la persona el sentido de la vida ni su orientación en el mundo.

\section{La inteligencia espiritual y la oración}

La vida espiritual en el ser humano se expresa como una modalidad intelectiva que lo faculta para procurar una vida orientada hacia la felicidad, el bienestar y lo simple (Velásquez, 2019, p. 245). La felicidad se entiende como el telos vital de la existencia humana, que es fruto de la formación del carácter (Shopenhahuer, 2003). La finalidad de la existencia está orientada hacia la felicidad porque constituye la esencia misma del sentido. Desde los griegos hasta los contemporáneos se ha abordado la cuestión de la felicidad como un elemento de capital importancia de la reflexión filosófica. Para Aristóteles el hombre virtuoso es aquel capaz de encontrar la justa medida de las cosas y por ello es potencialmente capacitado para ser feliz. Por el contrario, si el hombre sucumbe en los excesos de una vida superficial (Frankl, 2003, p. 17), carente de sentido, de forma inevitable es infeliz porque no verá colmada su existencia en los placeres vagos que proporciona la sociedad de consumo (Velásquez, 2019, p. 248). Según Aristóteles, el hombre es infeliz por la falta de equilibrio; por eso la vida profunda que permite al ser humano lograr la felicidad admite la formación del carácter.

La vida espiritual tiene como propósito la integración del ser humano hacia el afianzamiento de la heurística existencial. Es decir, el proyecto existencial del sentido conmina al ser humano a vivir plenamente feliz mediante el cultivo de la vida espiritual o, en términos de Torralba, de la inteligencia espiritual. De ahí que una vida auténtica es aquella que cultiva los valores de la vida espiritual $y$, de esta forma, se crea un nuevo arraigo hacia el pensamiento reflexivo que difícilmente nos ofrece el mundo de la técnica (Heidegger, 2002, p. 30). Así las cosas, el pensamiento reflexivo nos ayuda a tomar conciencia de nuestra propia 
existencia, de la finalidad objetiva de nuestro ser en el mundo y, además, de nuestra condición finita y vulnerable abierta a la experiencia del dolor.

Para Schopenhauer, desde Aristóteles, la felicidad consiste en reconocer el dolor como parte esencial de la vida humana y que, por ende, está vinculado a la capacidad de sufrimiento (2003). La felicidad y el dolor, como dos caras de la misma moneda, acaecen en la persona como su condición natural y, por tanto, al ámbito en el cual se resuelve el sentido de la vida. (Schopenhauer, 2005, p. 511). Si la felicidad es el telos vital de la existencia humana, no puede estar desligada del sufrimiento que comporta vivir. Allí donde sucede la felicidad, no como una ilusión del bienestar eterno, sino una acentuada visión de la realidad, acontece de igual forma la finitud del ser humano (Ricoeur, 2011). El carácter temporal del bienestar existencial, de lo que se podría llamar vida buena, no excluye la experiencia del dolor (Schopenhauer, 2003). Asumir la existencia en su totalidad hace parte de los frutos de la vida espiritual:

Los grandes sufrimientos y alegrías que se experimentan en las profundidades del ser conmueven y hacen vibrar nuestro interior. Cuando un ser humano cultiva su inteligencia espiritual, su ser permanece tranquilo, firme, impasible, pero no porque sea insensible, sino porque vive esos estados en toda su profundidad, como a distancia, pues su intimidad posee algo que permite hacer frente a todo lo que se le venga encima. (Torralba, 2018, pp. 256-257)

El cultivo de la vida espiritual resulta ser esencial cuanto más se vuelve preponderante la reclamación de lo humano en su integralidad: no se puede pretender pensar el sentido de la vida en el mundo contemporáneo sino se tiene en cuenta la condición finita de la existencia humana (Ricoeur, 2011). Ahora bien, una forma concreta de la toma de conciencia de la vida en su condición finita, vulnerable y conminada, de igual modo a la felicidad, es por medio de la oración; lo que en términos de Heidegger (2002) corresponde al pensamiento reflexivo (p. 28). Se entiende por oración la práctica espiritual que permite el cultivo de la vida interior del ser humano. La oración pertenece al patrimonio espiritual de la humanidad que no está afincada, como ya lo dijimos, a un credo en particular; es una capacidad existencial que, a través del silencio, la serenidad y la meditación, logra afianzar la vida meditativa, frente al hechizo del mundo virtualizado (Baudrillard, 2002).

La oración, como una actividad del espíritu, dinamiza las funciones del intelecto para resolver la problemática del sentido. Es problemático algo que está en el plano de la angustia (Torralba, 1998, p. 13). La oración enfrenta la angustia existencial cotidiana del sentido en la búsqueda por lo auténtico, cuya finalidad está orientada a procurar la felicidad, el bienestar y lo simple (Velásquez, 2019, p. 245). Orar es el amor hecho comunicación, las palabras son pretexto del discurso, 
como un accidente del proceso comunicativo. La dialogicidad del proceso comunicativo de la oración es metadiscursiva, en la cual el silencio, la serenidad y la meditación movilizan al ser humano a tomar distancia y conminar a la acción.

La persona es un ser en el mundo que, en su condición de arrojado (Heidegger, 2018), está capacitado para ver el mundo desde la distancia por la inteligencia espiritual. Ver el mundo desde la distancia es la forma como el ser humano hace de la oración un ejercicio espiritual y la forma loable para resolver la problemática del sentido. Si la oración es un proceso comunicativo intelectual, es válido afirmar que a través del discernimiento es como se logra dicho ascenso respecto al mundo, para tomar correctamente una decisión frente a los retos que depara la vida. El discernimiento faculta al ser humano para que, en el distanciamiento, pueda superar el estancamiento existencial (Velásquez, 2018, p. 102) y promover la vida en el entorno social que le ha sido dado.

Abordar la cuestión del sentido es a la vez preguntar por las estructuras humanas-sociales que posibilitan dicha indagación (Torralba, 2002, p. 143). Lo social es, ante todo, un hecho artificial (Arendt, 2019, p. 45) cuya naturalidad descubre la esencia misma del sentido. El ser social es artificial por el hecho de ser una construcción humana y es natural por la dinámica interactiva de la existencia: soy en el otro la posibilidad de sí mismo. El otro es posible porque existe un yointeractivo. La oración como comunicación exige la interacción perlocutiva de la persona con lo otro que, en su forma indeterminada y circunstancial, dirime la indagación existencial por el sentido de la vida. La práctica de la oración «conecta con la vida y en ella se prolonga». La función social de la oración distingue el lugar que debe ocupar la persona en el mundo, el para qué, la finalidad que suscita al interior de ella en su inevitable tarea hacia el otro. Soy en el mundo la posibilidad misma de la donación: la remoción del ser cuya vocación está en la dación de sí (Restrepo, 2012) y cuya dinámica vincula con las múltiples formas de la alteridad.

Por tal motivo se hace urgente y cada vez necesario cultivar la inteligencia espiritual para hacer frente al sinsentido de la vida al cual nos ha conducido el pensamiento calculador (Heidegger, 2002, p. 30). El cultivo del espíritu requiere esfuerzo, constancia, abnegación, sacrificio: es la devastación del ser por el desvío de lo otro. El espíritu humano se cultiva a través de ejercicios espirituales que facilitan tomar distancia del mundo cotidiano en sus múltiples avatares (Foucault, 2014). La rapidación, aceleración social sensitiva (Velásquez, 2017a) altera la lentitud de los procesos humanos (Francisco, 2015, párr. 18) y no permite reconocer a simple vista los beneficios de la vida espiritual.

La lentitud es la misteriosidad de la existencia, es decir, que al ser la vida un misterio, le corresponden, de igual forma, procesos lentos de indagación existencial, garantía para la correcta resolución a la pregunta por el sentido. 
Por eso es válido afirmar que desde el silencio, la serenidad y la meditación, el espíritu humano toma distancia del mundo cotidiano y enfrenta su conciencia para encarar la angustiosa tarea del pensamiento.

Se entiende por la expresión angustiosa tarea del pensamiento el ejercicio noético y existencial de carácter heurístico que mueve a la persona a despertar de su estado de anquilosamiento que ha sido ocasionado por la técnica como embeleco del pensamiento reflexivo (Velásquez, 2018) ¿Corresponde al espíritu humano un modo específico de abordar la cuestión del sentido?; ¿el pensamiento cotidiano no especializado es una forma concreta del intelecto humano espiritual?; ¿la indagación cognitiva del pensamiento no especializado responde a la dinámica espiritual del intelecto humano por la cuestión del sentido?; ¿es la oración, como modalidad propia de la inteligencia espiritual, una forma plausible en el mundo actual para abordar el sentido de la vida? En la base de estos cuestionamientos están implícitamente conectados el sentido de la vida, la oración, la toma de distancia y la apertura.

Lo cotidiano se caracteriza por ser impredecible y cede muchas veces al infortunio de la vida (Heidegger, 2018). Aunque el hombre contemporáneo exalta el pensamiento calculador en detrimento del pensamiento meditativo, lo cotidiano se escapa de cualquier programación sistemática del cálculo racional (Heidegger, 2002, p. 31). Lo impredecible acontece en la cotidianidad como manifestación dinámica de la vida. Esto permite que el ser humano cultive la capacidad de asombro respecto a la vida y en igual correspondencia estimule la esencia de la oración, como una modalidad específica del pensamiento reflexivo. Los acontecimientos cotidianos pueden ser objeto del pensamiento meditativo cuando se convierten en condición de posibilidad de la oración (Ricoeur, 1971); por eso la oración se conecta con la vida y en ella se prolonga. De ahí que, pensar la vida en el mundo contemporáneo sea un ejercicio meditativo a través de la oración.

La oración fortalece la capacidad de la contemplación, ver en profundidad la vida, ir más allá de lo evidente dado por la técnica, para reconocer la armonía caótica circunstancial del sentido (Velásquez, 2017a, p. 52). Orar es más que rezar, como la elucubración de fórmulas, ritos o esquemas. Orar es conectar el sentido de la vida con el mundo, conducir el pensamiento hacia la meditación en el silencio y la serenidad, como facilitadores de la actividad de introspección existencial. No resulta fácil reconocer la importancia de la oración sobre todo cuando la vida cotidiana se desenvuelve de forma predominante bajo el influjo de la técnica; y aunque sea inevitable no ceder al asecho de la programación sistemática dada por la sociedad de consumo (Baudrillard, 2009) y del cálculo matemático de la máquina que aprende a conocer, desde la apariencia, al ser humano que ha virtualizado su existencia (Velásquez, 2017a), no se puede dejar de insistir acerca de la importancia del cultivo de la vida espiritual como una 
modalidad específica de autenticidad para librar a la persona de la rutina y el tedio provocados por el estancamiento existencial y ocasionado por el hechizo virtual de la sociedad (Baudrillard, 2002).

El dispositivo virtual tiene información de los gustos, las tendencias y modas de las personas que permanecen en la red, producto del cálculo matemático algorítmico del sistema. Nos parece llamativo, por ejemplo, cómo la reconocida productora Warner Bros ha confiado a la inteligencia artificial la creación de tendencias de cine y el control de contratación de actores para un mayor impacto en el mercado (Peña, 2020); aunque algunos se muestren escépticos frente a esta nueva modalidad del mercado promocionado por la máquina, no deja de sorprender que la técnica ha logrado traspasar los linderos creativos de la acción humana.

El predominio de la técnica ha colonizado la esfera existencial del sentido (Velásquez, 2018), y la actividad cognitiva del ser humano ha quedado reducida a la mera participación en el mundo social desde la opinión arbitraria de los asuntos vitales de la existencia humana. No es la técnica en sí misma la que ha colonizado la vida del ser humano, sino la misma programación sistemática que ha cobrado autonomía y que poco a poco prescinde de la intervención humana (Heidegger, 2002).

Si el mundo de hoy ha relegado los beneficios de la vida espiritual es porque el pensamiento calculador de la técnica, como lo había predicho Heidegger, se ha vuelto el único modo de conocer la realidad, de constituir el mundo como representación y hechizar la mente del consumidor que inconscientemente accede a las demandas virtuales del consumo (Heidegger, 2002, p. 23).

La oración se constituye, en contra de la lógica virtual de dominación, en un modo privilegiado para direccionar la existencia, descubrir el sentido de la vida y cultivar una vida auténtica desde los beneficios del fomento de la vida espiritual. Esta práctica espiritual puede llegar a convertirse en un camino para la solución de conflictos existenciales en la actualidad; sin embargo, la oración está muy lejos de llegar a ser simplemente una herramienta. Si el pensamiento meditativo se cultiva a través de la oración tiene sentido pensar que a través de ella se puedan alcanzar caminos de realización humana. La oración es el amor hecho comunicación que conmina y rescata al otro del asedio cotidiano, del tedio virtual y el hastío de la vida: permite la contemplación de la vida simple (Velásquez, 2019) en la que se hace preponderante el cultivo de la inteligencia espiritual.

El ser humano está potencialmente capacitado para cultivar la vida en el espíritu de tal forma que a través de la oración descubre el sentido de la existencia. Ahora bien, la oración como forma loable para abordar la cuestión del sentido, articula en su discurso la forma originaria de la experiencia del amor que se hace 
donación, es decir, el orante comunica aquello que está llamado a resolver: la pregunta por el sentido de la vida en la realización auténtica de la donación, el amor que se comunica con gestos que ayudan a resolver el sentido de la vida orientada a la modalidad no especializada del servicio.

Si se insiste, de alguna manera, que la persona es en el otro la posibilidad de sí, quiere decir que a través del despertar existencial se puede dar cuenta del lugar que ocupa el otro en el cultivo de la vida espiritual. El Papa Francisco (2018) a propósito de esta realidad nos dice:

El consumismo hedonista puede jugarnos una mala pasada, porque en la obsesión por pasarla bien terminamos excesivamente concentrados en nosotros mismos, en nuestros derechos y en esa desesperación por tener tiempo libre para disfrutar. Será difícil que nos ocupemos y dediquemos energías a dar una mano a los que están mal si no cultivamos una cierta austeridad, si no luchamos contra esa fiebre que nos impone la sociedad de consumo para vendernos cosas, y que termina convirtiéndonos en pobres insatisfechos que quieren tenerlo todo y probarlo todo. También el consumo de información superficial y las formas de comunicación rápida y virtual pueden ser un factor de atontamiento que se lleva todo nuestro tiempo y nos aleja de la carne sufriente de los hermanos. En medio de esta vorágine actual, el Evangelio vuelve a resonar para ofrecernos una vida diferente, más sana y más feliz. (párr. 108)

De esta manera, la oración constituye un modo por el cual la persona descubre los beneficios de la vida espiritual para entender el sentido de la vida. Somos en los demás la posibilidad de una vida auténtica orientada en el servicio y la entrega generosa en un mundo individualista embelesado por la técnica. La orientación existencial se muestra como el descubrimiento progresivo y dinámico de acuerdo con la etapa de la vida en que se encuentra la persona que, desde las condiciones actuales (Velásquez, 2017a), se presenta en un estado de movimiento continuo.

\section{Conclusión: la oración y sentido de la vida}

La oración es la forma esencial en que la inteligencia espiritual posibilita la indagación progresiva por la existencia. Wittgenstein (1982) en su diario filosófico afirma: "pensar en el sentido de la vida es orar" (p. 126). Resulta interesante que haya una relación estrecha entre el sentido de la vida y la oración. El planteamiento de fondo es iqué se puede saber sobre Dios y la finalidad de la vida? La inteligencia espiritual confina todo su potencial a que el ser humano se dé la oportunidad para preguntarse por lo absoluto, que por su capacidad racional se abre al misterio de Dios en lo humano. Dios constituye, en la inteligencia espiritual, la base consistente que moviliza y unifica al ser humano hacia una vida plena y feliz. En Él se encuentra confinado el sentido pleno de la vida. Cada ser 
humano está en condición de posibilidad para desarrollar plenamente su vida en la ejercitación de la inteligencia espiritual y, de esta forma, resolver la angustiosa tarea del pensamiento cotidiano de la vida y el sentido.

Si, como ya se ha insistido, la oración es un patrimonio espiritual de la humanidad, ¿de qué manera entender esta propuesta desde las posiciones del ateísmo en su radical negación a Dios? Paul Ricoeur en El conflicto de las interpretaciones aborda el tema de religión, ateísmo y fe. La tesis principal del autor, en esta parte del libro, es demostrar que el ateísmo "no agota su significado en la negación y la destrucción de la religión, sino que libera el horizonte para algo más, para una fe susceptible de ser llamada — aun cuando sean necesarias precisiones ulteriores - 'fe posreligiosa', una fe para una edad posreligiosa" (Ricoeur, 2015b, p. 397).

Para demostrar lo anterior, Paul Ricoeur acude a Karl Marx, Friedrich Nietzsche y Sigmund Freud en sus principales críticas a la religión. Sin pretender abordar la complejidad de cada una de las críticas de los maestros de la sospecha, diremos que sus postulados se centraron en una crítica al dios moral que concluye "en una crítica de la religión como refugio y protección." (Ricoeur, 2015b, p. 410). Dicho de otra manera, tanto Marx, Nietzsche y Freud, desde sus críticas a la institución religiosa, proponen la liberación del ser humano del yugo opresor del dios moral de la religión. Además, declaran el fracaso del dios metafísico de la reflexión filosófica y teológica de corte trascendental, cuya elucubración especulativa daba cuenta de un dios inaccesible para el ser humano (Ricoeur, 2015b, p. 416).

Ricoeur propone, entonces, que el ateísmo contemporáneo, instaurado por influencia de Marx, Nietzsche y Freud, no es otro que la reivindicación de una fe religiosa auténtica, libre de la influencia del dios moral metafísico propuesto por la reflexión teológica y filosófica medieval y moderna, y sostenida por la institución religiosa en detrimento del ser humano. Así las cosas, el ateísmo, desde Ricoeur, es un nuevo despertar de la fe 'posreligiosa'. En este contexto se ubica la propuesta de entender que pensar en el sentido de la vida es orar. Si la oración pertenece al patrimonio espiritual de la humanidad, y de algún modo responde a una de la expresiones de la fe posreligiosa en el cultivo de la inteligencia espiritual por medio de la oración, entonces hoy es válido recalcar la importancia de la oración para determinar los alcances existenciales del proyecto de vida.

Orar es pensar la vida en relación con el mundo: la función social de la inteligencia espiritual. La interioridad en la persona responde a la necesidad espiritual de pensar el sentido de la vida en el mundo y se caracteriza por escudriñar, en lo profundo del ser, las cosas del espíritu. Se resalta, de este modo, la importancia de la meditación como una ejercitación del espíritu humano. El silencio, como condición de posibilidad de la meditación, facilita tomar distancia 
de la cotidianidad. La ejercitación del espíritu humano a través de prácticas de corte espiritual, tales como la contemplación y la meditación, entre otras, facilitan la resolución progresiva, no definitiva, de la pregunta por el sentido de la vida.

La inteligencia espiritual [énfasis añadido] da poder para convertir la vida en un proyecto, para ordenar las otras formas de inteligencia hacia el fin que libremente uno ha decidido. La realización personal de un proyecto de vida no es un repliegue narcisista sobre el propio yo, sino la posibilidad de ofrecerse a una tarea que transciende al yo. El sentido de la vida no se centra en uno mismo, sino que se nos abre a los otros. (Torralba, 2018, p. 253)

Así como la vida tiene sentido en relación con lo otro, también la oración busca conectar la vida del orante con la alteridad. Orar permite el distanciamiento de la vida cotidiana y, así mismo, provoca la apertura al mundo; es distanciamiento y apertura que asiente la riqueza de la vida espiritual en la modalidad no específica del servicio. La vida del orante se caracteriza por tener un fuerte sentido de realidad: reconoce la condición humana en su totalidad y es consciente de sus propias posibilidades y límites (Ricoeur, 2011). El orante que piensa la vida no lo hace arbitrariamente, sino concienzudamente, es decir, fruto de un ejercicio de introspección que deja ver en su naturaleza la dinámica de la vida espiritual. La vida del orante es consecuencia del cultivo de la inteligencia espiritual: asumir la valiente tarea del pensamiento angustioso del sentido en el mundo contemporáneo que hace frente a los mecanismos que aniquilan la actividad cognitiva del pensamiento meditativo (Heidegger, 2002).

La oración, como ejercicio espiritual, responde al llamado de la conciencia, que en el individuo se comporta como un hecho transcendental e inmanente, propio de la constitución antropológica del ser. La comunicación del orante establece una conexión con el mundo interior en el que se esclarecen los interrogantes del preguntar último (Torralba, 2018, p. 85). La conciencia establece este proceso comunicativo en el que en sí mismo se encuentra con la dimensión transcendental y absoluta. Orar tiene sentido si la vida misma se comprende como un misterio ineludiblemente humano. Así las cosas, la oración es un proceso intelectual que involucra, en su estructura, procesos metacognitivos que arrojan a la persona a tomar distancia del mundo meramente inmediato al poner en estrecha relación al ser humano con su mundo interior y el reconocimiento del otro.

El sentido aflora en las condiciones que garantizan la asunción espiritual del intelecto humano: el silencio, la serenidad y la meditación. El distanciamiento es fruto de la oración como un no-estar ahí que a la vez implica estar en la vida. 
No estar ahí no quiere decir en el sentido fáctico de la expresión; se refiere a la conciencia del no estar porque hace que el ser humano tome distancia espaciotemporal de lo inmediatamente presente para contemplar su narrativa existencial como trayectoria vital de realización humana (Torralba, 2018, p. 253).

En definitiva, pensar en el sentido de la vida es una actividad netamente del espíritu. Se puede abordar desde la oración porque en ella subyace un principio comunicativo-existencial que se basa en una profunda experiencia de amor que facilita a la persona, en el silencio, la serenidad y la meditación, confrontar la vida, resolver el sentido progresivo de la indagación existencial y la capacidad de proyectarse en el mundo en la modalidad no específica del servicio. El amor que se comunica en la oración se traduce en servicio. Pensar en el sentido de la vida es orar porque la oración lanza hacia el otro, que reclama en su rostro, la donación como experiencia del amor.

Pensar en el sentido de la vida es orar porque la oración implica el cultivo de la inteligencia espiritual. La inquietud de sí, la pregunta por el sentido, la sed de autenticidad, la necesidad de cultivar en la vida una espiritualidad como estilo de vida son tareas preponderantes en el mundo actual, y más aún si la vida se ve asediada por la fragmentación y disolución del ser debido a las dinámicas de la sociedad de consumo y del capitalismo informacional (Velásquez, 2019, p. 252).

Ya no se trata de una cuestión netamente de iniciados de la vida espiritual porque el ser humano está potencialmente capacitado para cultivar la oración como una forma de encarar la inquietud fundamental de la vida: el sentido de la existencia. La oración, en última instancia, es la comunicación del sentido de lo humano, sucinto en la naturaleza racional y emocional del pensamiento. Por tanto, la actividad del pensamiento es la acción humana que se logra por medio del intelecto que permite ir hacia la profundidad de las cosas (Torralba, 2018). De este modo, pensar en el sentido de la vida se logra a través del cultivo de la vida espiritual.

La inquietud de sí, el estado natural de la conciencia humana en la continua indagación de la existencia, remueve las entrañas del pensamiento y arroja a la persona fuera de sí para que, por medio de la oración, sea colmada en plenitud de sentido. El ser humano descentrado reconoce en el servicio la modalidad específica de la donación cuya comunicación amorosa se hace efectiva en la oración. El servicio es correlativo al pensamiento y, por ende, a la oración, porque allí donde actúa el orante acontece el sentido del ser humano en la develación de la conciencia del Ilamado. 


\section{Referencias}

Arendt, H. (2019). ¿Qué es la política?. Paidós.

Baudrillard, J. (2002). La ilusión vital. Siglo XXI Editores.

Baudrillard, J. (2009). La sociedad de consumo. Sus mitos y sus estructuras. Siglo XXI Editores.

Elizalde, P. M. (1986). Los dichos de los Padres de la Iglesia. Colección alfabética de los apotegmas. Paulinas.

Foucault, M. (2014). La hermenéutica del sujeto. Fondo de Cultura Económica.

Francisco [Papa] (2015). Carta Encíclica Laudato Si' sobre el cuidado de la casa común. Paulinas.

Francisco [Papa] (2018). Exhortación Apostólica Gaudete et exsultate sobre el llamado a la santidad en el mundo actual. San Pablo.

Frankl, V. (2003). Ante el vacío existencial. Hacia una humanización de la psicoterapia. Herder.

Frankl, V. (2010). Psicoanálisis y existencialismo: de la psicoterapia a la logoterapia. Fondo Cultura Económica.

Heidegger, M. (2002). Serenidad. Ediciones del Serbal.

Heidegger, M. (2018). El ser y el tiempo. Fondo de Cultura Económica.

Heller, A. (1998). Sociología de la vida cotidiana. Península.

Horkheimer, M. y Adorno, T. (1998). Dialéctica de la ilustración: fragmentos filosóficos. Trotta.

Peña, J. C. (9 de enero de 2020). Con AI Warner decidirá qué actores contratar y qué películas hacer. El Universal. https://www.eluniversal.com.mx/techbit/ con-ai-warner-decidira-que-actores-contratar-y-que-peliculas-hacer

Ricoeur, P. (1971). Acontecimiento y sentido. Universidad de París.

Ricoeur, P. (2001). Del texto a la acción. Fondo de Cultura Económica. 
Ricoeur, P. (2006). Sí mismo como otro. Siglo XXI Editores.

Ricoeur, P. (2008). Fe y filosofía. Problemas del lenguaje religioso. Prometeo libros.

Ricoeur, P. (2011). Finitud y culpabilidad. Trotta.

Ricoeur, P. (2015a). Amor y justicia. Siglo XXI Editores.

Ricoeur, P. (2015b) El conflicto de las interpretaciones. Fondo de Cultura Económica.

Restrepo, C. E. (2012). La remoción del ser. La superación teológica de la metafísica. San Pablo.

Schopenhauer, A. (2003). El arte de ser feliz. Herder.

Schopenhauer, A. (2005). El mundo como voluntad y representación. Trotta.

Segundo, J. L. (1982). El hombre de hoy ante Jesús de Nazaret. I Fe e ideología. Ediciones Cristiandad.

Torralba, F. (1998). Poética de la libertad, lectura de Kierkegaard. Caparrós.

Torralba, F. (2002) Ética del cuidar. Fundamentos, contextos y problemas. Instituto Borja de Bioética.

Torralba, F. (2018). Inteligencia espiritual. Plataforma.

Velásquez, E. (2015). La sociedad de consumo en La Caverna de Saramago. La aplicación de la función purgativa de la obra literaria. Escritos, 23(51), 497524.

Velásquez, E. (2017a). La dimensión temporal del Dasein en la era virtual: para una hermenéutica existencial del tiempo. Versiones $2^{\circ}$ época, 11(11), 40-68.

Velásquez, E. (2017b). La virtualización en el escenario contemporáneo de la educación. Editorial Académica Española.

Velásquez, E. (2018). Discursos vacíos para oídos estancados: hacia una hermenéutica de la acción. Revista de Filosofía de la UCSC, 17(1), 91-115.

Velásquez, E. (2019). Elogio a lo simple en tiempos del consumismo y del capitalismo informacional. Revista Ciencias y Humanidades, 8(8), 245-268.

Wittgenstein, L. (1982). Diario filosófico. Editorial Ariel. 